\title{
New Electronically-Controllable Lossless Synthetic Floating Inductance Circuit Using Single VDCC
}

\author{
Dinesh Prasad $^{1 *}$, Javed Ahmad ${ }^{2}$ \\ ${ }^{1}$ Department of Electronics and Communication Engineering, Faculty of Engineering \\ and Technology, Jamia Millia Islamia, New Delhi, India \\ ${ }^{2}$ Department of Electronics and Communication Engineering, \\ Maharaja Agrasen Institute of Technology, Rohini, New Delhi, India \\ Email: *dprasad@jmi.ac.in, javedahmade@gmail.com
}

Received November 8, 2013; revised December 8, 2013; accepted December 15, 2013

Copyright (C) 2014 Dinesh Prasad, Javed Ahmad. This is an open access article distributed under the Creative Commons Attribution License, which permits unrestricted use, distribution, and reproduction in any medium, provided the original work is properly cited. In accordance of the Creative Commons Attribution License all Copyrights (C) 2014 are reserved for SCIRP and the owner of the intellectual property Dinesh Prasad, Javed Ahmad. All Copyright (C) 2014 are guarded by law and by SCIRP as a guardian.

\section{ABSTRACT}

A new electronically-controllable lossless floating inductance (FI) circuit (without any matching condition) has been presented, which employs only one Voltage Differencing Current Conveyor (VDCC), one grounded capacitor and one grounded resistor. The main aim of the paper is to present a new floating inductance simulator using single active device with minimum passive components. The proposed floating inductance simulator can be electronically controllable by changing the bias current. The workability of the new presented FI circuit has been verified using SPICE simulation with TSMC CMOS $0.18 \mu \mathrm{m}$ process parameters.

\section{KEYWORDS}

\section{VDCC; Floating Inductance Simulation; Filters}

\section{Introduction}

Although many circuits for the simulation of grounded and floating inductance using different active building blocks such as operational amplifiers [1-5], current conveyors [6-13], current feedback amplifiers [14,15], current differencing buffered amplifiers [16,17], current differencing transconductance amplifiers [18,19], operational transconductance amplifiers [20,21], operational mirrored amplifiers [22], voltage differencing differential input buffered amplifiers [23,24], and voltage differencing transconductance amplifier [25] have been reported in the literature. In [26], many active building blocks have been presented, and VDCC is one of them. The usefulness of recently introduced active building block "VDCC" is well-defined in [27]. In [27], the authors proposed grounded inductance simulator circuits using single VDCC and two passive components. To the best knowledge of the author, no floating inductance simulator circuit using single VDCC and two passive compo-

${ }^{*}$ Corresponding author. nents has been reported in the open literature so far.

Therefore, the main objective of this paper is to propose a new circuit which employs one VDCC, one grounded capacitor and one grounded resistor to realize electronically-controllable lossless matchless FI circuit. The presented circuit has also the features like only two passive components (i.e. one grounded capacitor (as desired for IC implementation) and one grounded resistor) and low active and passive sensitivities. The validity of the presented new circuit has been verified using SPICE simulation with TSMC CMOS $0.18 \mu \mathrm{m}$ process parameters.

\section{The Proposed New Configuration}

The symbolic notation of recently proposed active building block, VDCC is shown in Figure 1, where $\mathrm{P}$ and $\mathrm{N}$ are input terminals and $\mathrm{Z}, \mathrm{X}, \mathrm{W}_{\mathrm{P}}$ and $\mathrm{W}_{\mathrm{N}}$ are output terminals. All of the terminals exhibit high impedance, except the $\mathrm{X}$ terminals [27]. The VDCC is characterized by the Equation (1). 


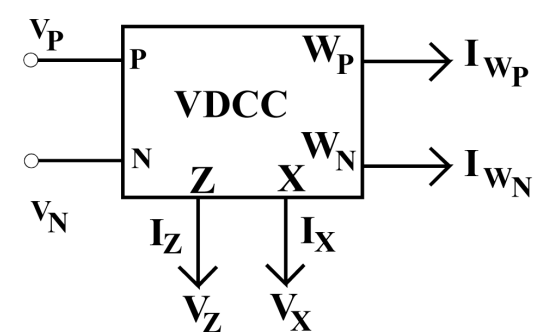

Figure 1. The symbolic notation of VDCC.

$$
\left[\begin{array}{c}
I_{N} \\
I_{P} \\
I_{Z} \\
V_{X} \\
I_{W_{P}} \\
I_{W_{N}}
\end{array}\right]=\left[\begin{array}{cccc}
0 & 0 & 0 & 0 \\
0 & 0 & 0 & 0 \\
g_{m} & -g_{m} & 0 & 0 \\
0 & 0 & 1 & 0 \\
0 & 0 & 0 & 1 \\
0 & 0 & 0 & -1
\end{array}\right]\left[\begin{array}{c}
V_{P} \\
V_{N} \\
V_{Z} \\
I_{X}
\end{array}\right]
$$

The proposed FI circuit is shown in Figure 2.

A routine circuit analysis of the new FI circuit shown in Figure 2 yields

$$
\left[\begin{array}{l}
I_{1} \\
I_{2}
\end{array}\right]=\frac{g_{m}}{s C R}\left[\begin{array}{ll}
+1 & -1 \\
-1 & +1
\end{array}\right]\left[\begin{array}{l}
V_{1} \\
V_{2}
\end{array}\right]
$$

which shows that the circuit simulates a floating lossless electronically-controllable inductance with the inducbtance value given by

$$
L_{e q}=\frac{C R}{g_{m}}
$$

\section{Non-Ideal Analysis and Sensitivity Performance}

The proposed FI circuit consisting various non-ideal parasitics is shown in Figure 3. The X-terminal parasitic impedance consisting of a resistance $R_{p_{2}}$ in series with inductance $L_{x}$, the parasitic impedance at the $\mathrm{W}_{\mathrm{P}}$-terminal consisting of a resistance $R_{p_{1}}$ in parallel with capacitance $C_{p_{1}}$, the parasitic impedance at the $\mathrm{W}_{\mathrm{N}^{-}}$ terminal consisting of a resistance $R_{p_{4}}$ in parallel with capacitance $C_{p_{4}}$ and the parasitic impedance at the Zterminal consisting of a resistance $R_{p_{3}}$.

For the circuit shown in Figure 3 , the input-output currents and voltages relationship is given by

$$
\left[\begin{array}{l}
I_{1} \\
I_{2}
\end{array}\right]=X\left[\begin{array}{cc}
s C_{p_{4}}+\frac{1}{R_{p_{4}}} & -1 \\
X & s C_{p_{1}}+\frac{1}{R_{p_{1}}} \\
-1 & 1+\frac{X}{X}
\end{array}\right]\left[\begin{array}{c}
V_{1} \\
V_{2}
\end{array}\right]
$$

where

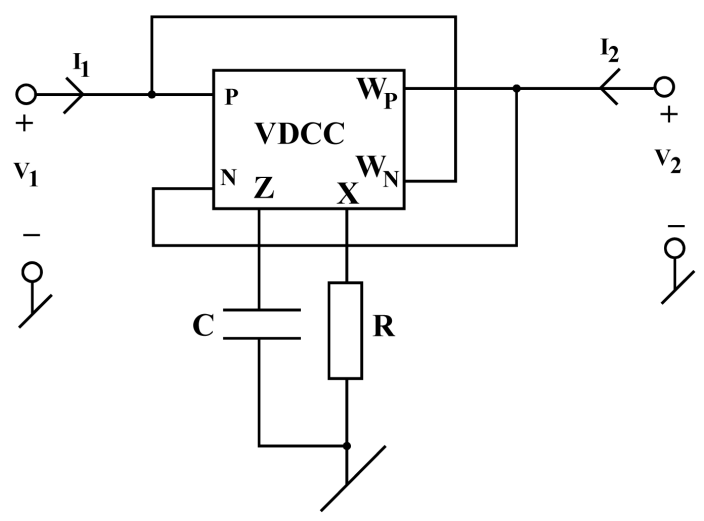

Figure 2. Proposed FI circuit.

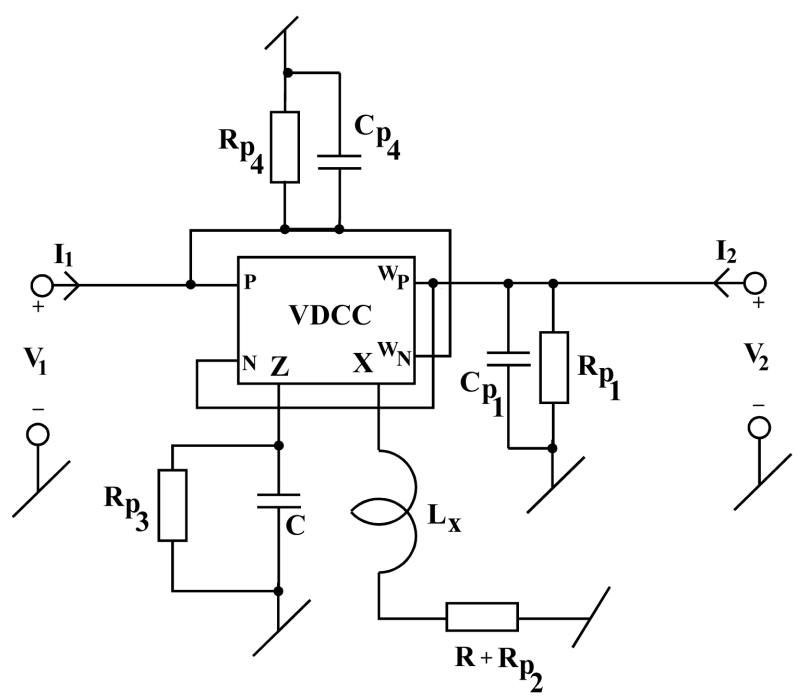

Figure 3. Proposed FI circuit including parasitic.

$$
X=\left(\frac{1}{s^{2} \frac{L_{x} C}{g_{m}}+s\left(\frac{C\left(R+R_{p_{2}}\right)}{g_{m}}+\frac{L_{x}}{R_{p_{3}} g_{m}}\right)+\left(\frac{R+R_{p_{2}}}{R_{p_{3}} g_{m}}\right)}\right)
$$

The non-ideal equivalent circuit of FI of Figure 3 is derivable from Equation (4) and is shown in Figure 4.

Where $L_{F I}=\frac{C R}{g_{m}}$ and $R=\frac{R+R_{p_{2}}}{R_{p_{3}} g_{m}}, \quad D=\frac{L_{x} C}{g_{m}}$, $L=\frac{C\left(R+R_{p_{2}}\right)}{g_{m}}+\frac{L_{x}}{R_{p_{3}} g_{m}}$

The various sensitivities of $L_{F I}$ with respect to active and passive elements are:

$$
S_{C}^{L_{F I}}=1, S_{g_{m}}^{L_{F I}}=-1, S_{R}^{L_{F I}}=1
$$

Thus, all the passive and active sensitivities of FI circuit are low. 


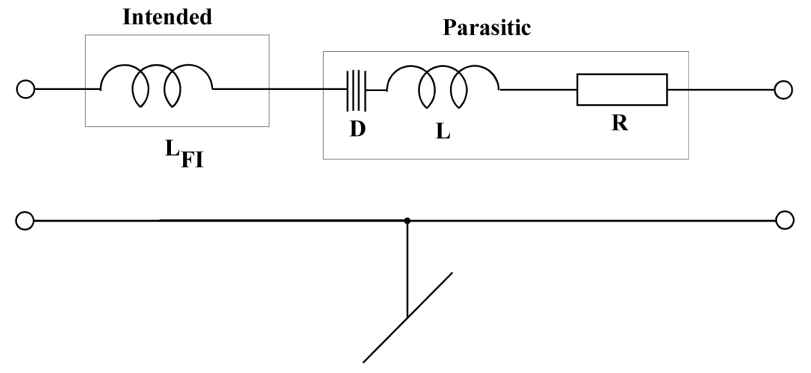

Figure 4. Non-ideal equivalent circuit of Figure 3.

\section{Application Examples of New FI Circuit}

The workability of the proposed FI circuits are demonstrated by realizing (i) a band pass filter (BPF) (Figure 5) and (ii) a fourth order Butterworth low pass filter with a cutoff frequency $500 \mathrm{kHz}$ was designed using the normalised proto-type shown in Figure 6 [15].

The transfer function realized by the configuration shown in Figure 5 is given by

$$
\frac{V_{0}}{V_{i n}}=\frac{s\left(\frac{g_{m}}{C_{1}}\right)}{s^{2}+s\left(\frac{g_{m}}{C_{1}}\right)+\frac{g_{m}}{C_{1} C_{2} R_{2}}}
$$

From Equation (6), it is clear that centre frequency is tunable by $R_{2}$.

The performance of the proposed FI circuit was verified by SPICE simulations. The frequency response of the FI circuit was obtained by using CMOS-based VDCC [27]. The following values were used for FI circuit: $\mathrm{C}=$ $0.01 \mathrm{nF}, \mathrm{g}_{\mathrm{m}}=277.833 \mu \mathrm{A} / \mathrm{V}, \mathrm{R}=10 \mathrm{k} \Omega$. From the frequency response of the simulated FI circuit (Figure 7) it has been observed that the inductance value remains constant upto $10 \mathrm{MHz}$.

The application circuits shown in Figures 5 and 6 were also been simulated using CMOS VDCCs. The component values used were for Figures 5: $\mathrm{C}_{1}=0.01 \mathrm{nF}$, $\mathrm{C}_{2}=0.02 \mathrm{nF}, \mathrm{R}_{1}=10 \mathrm{k} \Omega, \mathrm{R}_{2}=3.6 \mathrm{k} \Omega, \mathrm{g}_{\mathrm{m}}=277.833$ $\mu \mathrm{A} / \mathrm{V}$ and for Figure 6: $\mathrm{R}_{\mathrm{S}}=\mathrm{R}_{\mathrm{L}}=1 \mathrm{~K} \Omega, \mathrm{L}_{1 \mathrm{~d}}=0.2437$ $\mathrm{mH}\left(\mathrm{g}_{\mathrm{m}}=277.833 \mu \mathrm{A} / \mathrm{V}, \mathrm{C}_{1}=0.01 \mathrm{nF}, \mathrm{R}_{1}=6.77 \mathrm{k} \Omega\right)$, $\mathrm{L}_{2 \mathrm{~d}}=0.5884 \mathrm{mH}\left(\mathrm{g}_{\mathrm{m}}=277.833 \mu \mathrm{A} / \mathrm{V}, \mathrm{C}_{2}=0.01 \mathrm{nF}, \mathrm{R}_{1}\right.$ $=16.225 \mathrm{k} \Omega$ ), $\mathrm{C}_{1 \mathrm{~d}}=0.5884 \mathrm{nF}, \mathrm{C}_{2 \mathrm{~d}}=0.2437 \mathrm{nF}$ (after appropriate frequency and impedance scaling). The VDCC were biased with \pm 0.9 volts D.C. power supplies with $\mathrm{I}_{\mathrm{B} 1}=50 \mu \mathrm{A}$ (for $\mathrm{g}_{\mathrm{m}}=277.833 \mu \mathrm{A} / \mathrm{V}$ ). Figures 8 and 9 show the simulated band pass filter and $4^{\text {th }}$-order Butterworth filter responses respectively. A comparison of proposed FI with other published floating inductor is shown in Table 1.

Thus, the above simulation results confirm the validity of the applications of the proposed FI circuit.

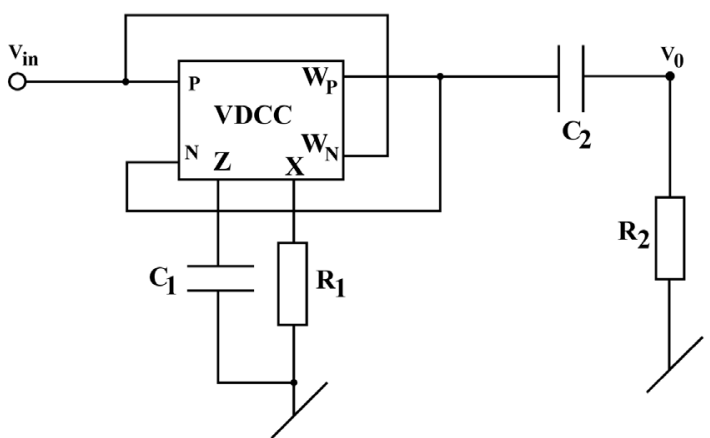

Figure 5. Band pass filter realized by the new FI circuit of Figure 2.

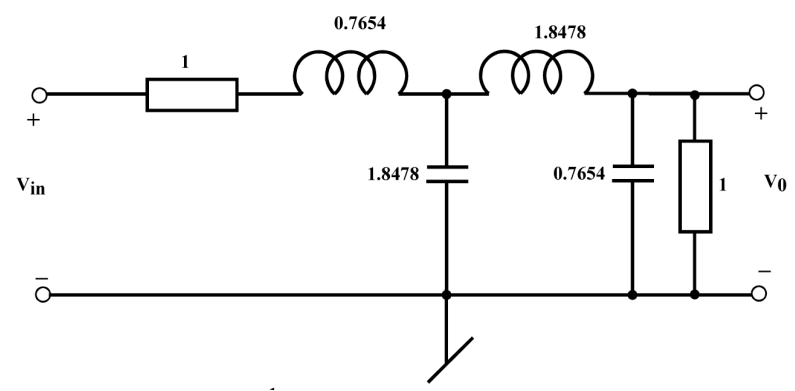

Figure 6. Normalised $4^{\text {th }}$-order Butterworth Low Pass Filter.

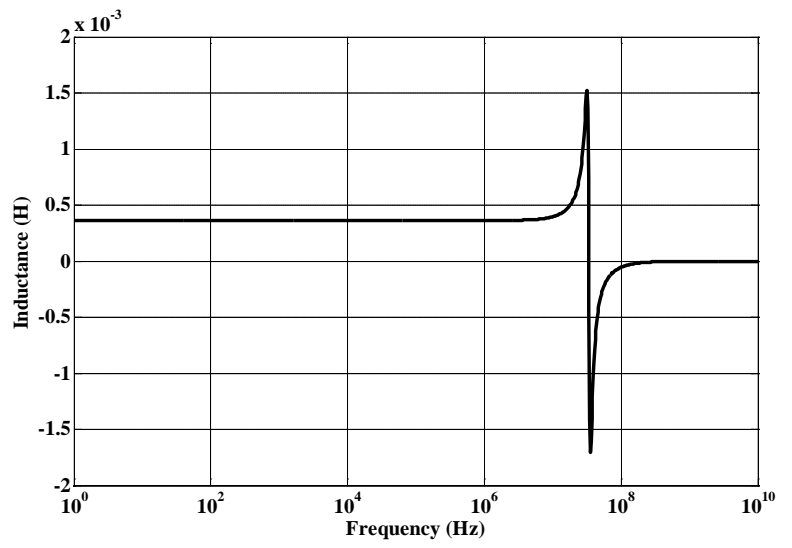

Figure 7. Frequency response of the simulated floating inductor.

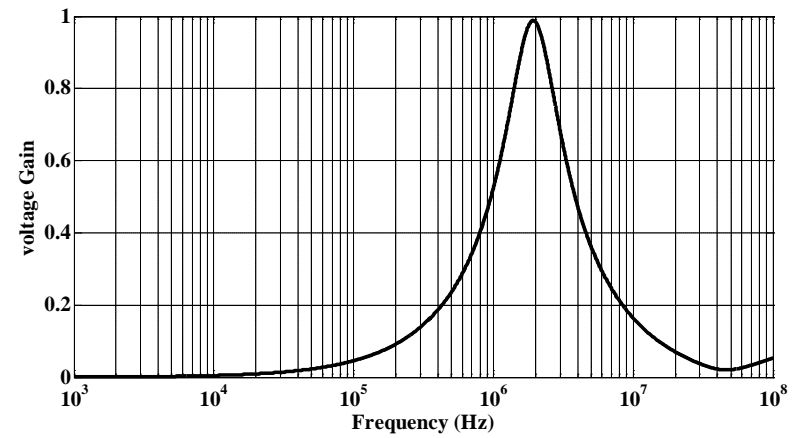

Figure 8. Frequency response of BPF using the proposed simulated FI. 
Table 1. Comparison of proposed FI circuit with other previously published floating inductors.

\begin{tabular}{|c|c|c|c|c|c|c|}
\hline Reference & Induct-ance type & No. of active device used & No. of resistors & No. of capacitors & $\begin{array}{l}\text { Matching condition } \\
\text { required }\end{array}$ & $\begin{array}{l}\text { Whether electronically } \\
\text { controllable }\end{array}$ \\
\hline [4] & Floating & 3 & 3 & 1 & Yes & No \\
\hline$[6]$ & Floating & $3 / 2$ & 2 & 1 & No & No \\
\hline$[7]$ & Floating & 4 & 4 & 1 & Yes & No \\
\hline$[8]$ & Floating & 4 & 3 & 1 & Yes & No \\
\hline [9] & Floating & 4 & 2 & 1 & No & No \\
\hline$[10]$ & Floating & 4 & 2 & 1 & No & No \\
\hline$[11]$ & Floating & 2 & 2 & 1 & No & No \\
\hline$[15]$ & Floating & 2 & 3 & 2 & Yes & No \\
\hline$[16]$ & Floating & $3 / 4$ & 4 & 1 & Yes & Yes \\
\hline$[17]$ & Floating & 3 & 0 & 1 & Yes & Yes \\
\hline [18] & Floating & 3 & 0 & 1 & Yes & Yes \\
\hline$[22]$ & Floating & 3 & 2 & 1 & No & No \\
\hline \multirow[t]{2}{*}{ [25] } & Grounded & 1 & 0 & 1 & No & Yes \\
\hline & Floating & 2 & 0 & 1 & Yes & Yes \\
\hline \multirow[t]{2}{*}{ [23] } & Grounded & 1 & 1 & 1 & No & Yes \\
\hline & Floating & 2 & 2 & 2 & Yes & Yes \\
\hline Proposed & Floating & 1 & 1 & 1 & No & Yes \\
\hline
\end{tabular}

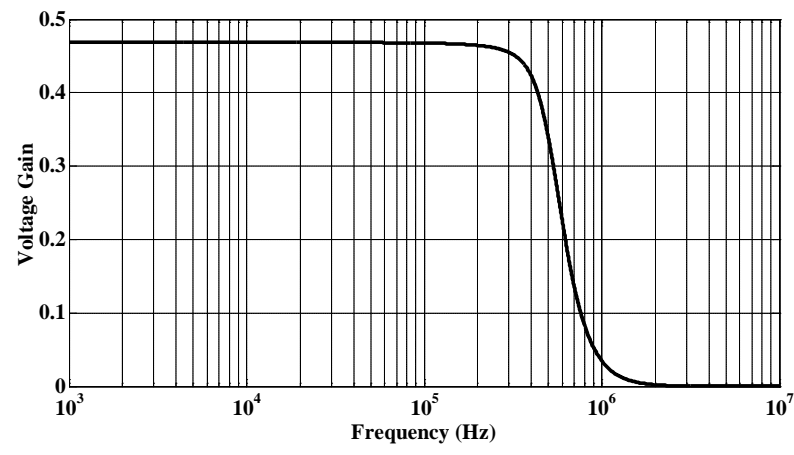

Figure 9. Frequency response of $4^{\text {th }}$-order Butterworth LPF.

\section{Conclusions}

A new electronically-controllable loss-less FI circuit without any matching condition has been proposed which employs one VDCC, one grounded capacitor and one grounded resistor. The proposed circuit offers the following advantageous features: 1) only two passive components i.e. one grounded capacitor (as desired for IC implementation) and one grounded resistor; 2) no matching condition; 3) fully electronically controllable (by changing bias currents); and 4) low active and passive sensitivities. The SPICE simulation results have con- firmed the workability of the new proposed floating inductance circuit.

\section{REFERENCES}

[1] A. Antoniou, "Gyrators Using Operational Amplifiers," IEEE Electronics Letters (UK), Vol. 3, No. 8, 1967, pp. 350-352.

[2] A. Antoniou, "Realisation of Gyrators Using Op-Amps and Their Use in RC Active Network Synthesis," Proceedings of the IEEE, Vol. 116, 1969, pp. 1838-1850.

[3] R. Senani, "New Single-Capacitor Simulations of Floating Inductors," Electrocomponent Science and Technology, Vol. 10, No. 1, 1982, pp. 7-10. http://dx.doi.org/10.1155/APEC.10.7

[4] R. Senani, "Realization of Single Resistance-Controlled Lossless Floating Inductance,” IEEE Electronics Letters (UK), Vol. 14, No. 25, 1978, pp. 828-829.

[5] R. Senani, “Three Op-Amp Floating Immittance Simulators: A Retrospection,” IEEE Transactions on Circuits and Systems II, Vol. 36, No. 11, 1989, pp. 1463-1465.

[6] R. Senani, "New Tunable Synthetic Floating Inductors," IEEE Electronics Letters (UK), Vol. 16, No. 10, 1980, pp. 382-383.

[7] K. Pal, "Novel Floating Inductance Using Current Conveyors,” IEEE Electronics Letters (UK), Vol. 17, No. 18, 1981, p. 638. 
[8] V. Singh, “Active RC Single-Resistance-Controlled Lossless Floating Inductance Simulation Using Single Grounded Capacitor," IEEE Electronics Letters (UK), Vol. 17, No. 24, 1981, pp. 920-921.

[9] R. Senani, "Novel Lossless Synthetic Floating Inductor Employing a Grounded Capacitor," IEEE Electronics Letters (UK), Vol. 18, No. 10, 1982, pp. 413-414.

[10] W. Kiranon and P. Pawarangkoon, "Floating Inductance Simulation Based on Current Conveyors," IEEE Electronics Letters (UK), Vol. 33, 1997, pp. 1748-1749.

[11] P. V. Anand Mohan, "Grounded Capacitor Based Grounded and Floating Inductance Simulation Using Current Conveyors,” IEEE Electronics Letters (UK), Vol. 34, No. 11, 1998, pp. 1037-1038.

[12] H. Sedef, and C. Acar, “A New Floating Inductor Circuit Using Differential Voltage Current Conveyors,” Frequenz: Journal of RF-Engineering and Telecommunications (Germany), Vol. 54, 2000, pp. 123-125.

[13] O. Cicekoglu, “Active Simulation of Grounded Inductors with CCII+s and Grounded Passive Elements," International Journal of Electronics, Vol. 85, No. 4, 1998, pp. 455-462. http://dx.doi.org/10.1080/002072198134003

[14] A. Fabre, "Gyrator Implementation from Commercially Available Trans Impedance Operational Amplifiers,” IEEE Electronics Letters (UK), Vol. 28, No. 3, 1992, pp. 263264.

[15] R. Senani and D. R. Bhaskar, "New Lossy/Loss-Less Synthetic Floating Inductance Configuration Realized with Only Two CFOAs," Analog Integrated Circuits and Signal Processing, Vol. 73, No. 3, 2012, pp. 981-987. http://dx.doi.org/10.1007/s10470-012-9897-5

[16] A. U. Keskin and H. Erhan, "CDBA-Based Synthetic Floating Inductance Circuits with Electronic Tuning Properties,” ETRI Journal, Vol. 27, No. 2, 2005, pp. 239-242. http://dx.doi.org/10.4218/etrij.05.0204.0055

[17] W. Tangsrirat and W. Surakampontorn, "Electronically Tunable Floating Inductance Simulation Based on CurrentControlled Current Differencing Buffered Amplifiers,” Thammasat International Journal of Science and Technology, Vol. 11, No. 1, 2006, pp. 60-65.

[18] D. Biolek and V. Biolkova, “Tunable Ladder CDTA-Based Filters,” 4th Multiconference WSEAS, Spain, 2003, pp.
$1-3$.

[19] D. Prasad, D. R. Bhaskar and A. K. Singh, "New Grounded and Floating Simulated Inductance Circuits Using Current Differencing Transconductance Amplifiers,” Radioengineering Journal, Vol. 19, No. 1, 2010, pp. 194198.

[20] R. Nandi, "Lossless Inductor Simulation: Novel Configurations Using DVCCs,” IEEE Electronics Letters (UK), Vol. 16, No. 17, 1980, pp. 666-667.

[21] M. T. Abuelma'atti, M. H. Khan and H. A. Al-Zaher, "Simulation of Active-Only Floating Inductance,” Frequenz: Journal of RF-Engineering and Telecommunications (Germany), Vol. 52, 1998, pp. 161-164.

[22] R. Senani and J. Malhotra, "Minimal Realizations of a Class of Operational Mirrored Amplifier Based Floating Impedance,” IEEE Electronics Letters (UK), Vol. 30, No. 14, 1994, pp. 1113-1114.

[23] D. Prasad, D. R. Bhaskar and K. L. Pushkar, "Realization of New Electronically Controllable Grounded and Floating Simulated Inductance Circuits Using Voltage Differencing Differential Input Buffered Amplifiers,” Active and Passive Electronic Components (USA), 2011, Article ID: 101432

[24] D. R. Bhaskar, D. Prasad and K. L. Pushkar, "Electronically-Controllable Grounded-Capacitor-based Grounded and Floating Inductance Simulated Circuits Using VDDIBAs," Circuits and Systems (USA), Vol. 4, No. 5, 2013, pp. 422-430. http://dx.doi.org/10.4236/cs.2013.45055

[25] D. Prasad and D. R. Bhaskar, "Grounded and Floating Inductance Simulation Circuits using VDTAs," Circuits and Systems (USA), Vol. 3, No. 4, 2012, pp. 342-347. http://dx.doi.org/10.4236/cs.2012.34048

[26] D. Biolek, R. Senani, V. Biolkova and Z. Kolka, “Active Elements for Analog Signal Processing; Classification, Review and New Proposals,” Radioengineering, Vol. 17, No. 4, 2008, pp. 15-32.

[27] F. Kacar, A. Yesil, S. Minaei and H. Huntman, "Positive/ Negative Lossy/Lossless Grounded Inductance Simulators Employing Single VDCC and Only Two Passive Elements,” AEU-International Journal of Electronics and Communications, in Press. 